\title{
Social Influences on Phonological Transfer: /r/ Variation in the Repertoire of Welsh-English Bilinguals
}

\author{
Jonathan Morris (D)
}

Citation: Morris, Jonathan. 2021. Social Influences on Phonological Transfer: / $\mathrm{r} /$ Variation in the Repertoire of Welsh-English Bilinguals. Languages 6: 97. https://doi.org/10.3390/languages 6020097

Academic Editors: Juana M. Liceras and Raquel Fernández Fuertes

Received: 22 March 2021

Accepted: 19 May 2021

Published: 25 May 2021

Publisher's Note: MDPI stays neutral with regard to jurisdictional claims in published maps and institutional affiliations.

Copyright: (C) 2021 by the author. Licensee MDPI, Basel, Switzerland. This article is an open access article distributed under the terms and conditions of the Creative Commons Attribution (CC BY) license (https:// creativecommons.org/licenses/by/ $4.0 /)$.
School of Welsh, Cardiff University, Cardiff CF10 3EU, UK; morrisj17@caerdydd.ac.uk

\begin{abstract}
It is well known that cross-linguistic interactions can exist between the two languages in a bilingual speaker's repertoire. At the level of phonetics and phonology, this interaction may result in the transfer of a feature from one language to the other or the 'merging' of phonetic properties between languages. Although there are numerous studies of bilingual speakers which show such interactions, relatively little is known about the nature of transfer in communities of long-term bilingualism. The current study investigates phonological transfer of /r/ in Welsh-English bilinguals' speech in north Wales. Specifically, it compares the influence of speaker gender, home language, and speech context on the production of / $\mathrm{r} /$ in both English and Welsh in two communities which differ in the extent to which Welsh is spoken as a community language. It is commonly assumed that the alveolar trill $[\mathrm{r}]$ and alveolar tap $[r]$ are the variants of $/ \mathrm{r} /$ in Welsh. In English, the alveolar approximant $[x]$ is typical across Wales, but the trill and tap are reported in areas where a high proportion of the population speaks Welsh. Data in both languages were collected from 32 WelshEnglish bilinguals (aged 16-18) via sociolinguistic interview and wordlist tasks. The sample was stratified equally by speaker gender, home language, and area (predominantly Welsh-speaking vs. predominantly English-speaking). The results show areal differences in the production of $/ \mathrm{r} /$ in both languages, which, I argue, could be attributed partly to differing social structures in the communities under investigation. Consequently, the results showed evidence of bi-directional phonological transfer, which is community-specific and influenced by a number of social factors.
\end{abstract}

Keywords: language variation; bilingualism; phonological transfer; Welsh; Welsh English

\section{Introduction}

The interaction between the sound systems of a bilingual's languages can be attributed to (1) cross-linguistic interactions at the level of phonetics, whereby the phonetic implementation of a particular sound might be influenced to varying degrees by the other language(s) in a speaker's repertoire (e.g., Mennen 2004; Simonet 2010; Mayr and Montanari 2015; Simonet 2014; Simonet and Amengual 2020), or (2) the 'wholesale' transfer of features from one language to another (see Odlin 1989). More specifically, the process of phonological transfer in synchronic speech describes the substitution of phonemic segments, phonotactic patterns, and prosodic features from one language in another (Simon 2010, p. 63). This results in the production of features typically associated with one of the bilingual speaker's languages in the other language. The extent to which this process is realised in speech has been well-studied in the field of Second Language Acquisition (SLA) and can depend on a number of factors including age of acquisition, level of formal instruction, use of the two languages, social networks, the interlocutor, and the speech context (see Piske et al. 2001; Grosjean 2001 for overviews).

The current study contributes to a growing body of variationist work examining transfer in situations of long-term bilingualism (e.g., Davidson 2015; Nagy 2015; Mooney 2019; Gafter and Horesh 2020). One particular strand of this research has been the analysis of speech in contexts of language revitalisation, wherein a clear distinction in speech patterns has been found between so-called 'new speakers', who have acquired the language 
outside of the home, and 'traditional speakers' (e.g., Nance 2013, 2015). In the case of Welsh-English bilingualism, however, previous work on monophthong and lexical stress production in one community has shown few cross-linguistic differences and little influence of extra-linguistic factors such as the home language of the speaker (e.g., Morris 2017; Mayr et al. 2017; Mennen et al. 2020).

The study builds on previous work (1) by examining a consonantal feature that exhibits clear cross-linguistic differences between Welsh and English (the patterning of which has hitherto not been quantified) and (2) by comparing two communities. Ultimately, this advances our knowledge of the ways in which local community social structures might influence transfer in situations of long-term bilingualism. Specifically, I report on an analysis of the influence of linguistic and extra-linguistic factors on the production of / $\mathrm{r} /$ in the Welsh and English of 32 bilingual speakers aged 16-18 in the towns of Mold (Flintshire) and Caernarfon (Gwynedd). The two towns have comparable populations but differ in the extent to which Welsh is spoken.

Section 2 outlines the background of the study and focuses on previous studies of crosslinguistic interactions in the speech of Welsh-English bilinguals, previous studies of the / $\mathrm{r} /$ production in both languages, and research questions. Section 3 provides background on the community, speakers, and methodological approach in the study. Section 4 presents the analysis of the results, and these results are discussed with reference to the research questions in Section 5.

\section{Background}

\subsection{The Welsh Context}

The Welsh language is spoken by approximately $19 \%(n=562,016)$ of the population of Wales (Welsh Government 2012). The concentration of Welsh speakers in a given area varies throughout Wales, and in some western areas, Welsh is spoken by the majority of the local population. For instance, $65.4 \%(n=77,000)$ of the population of the western county of Gwynedd are bilingual, compared to $7.8 \%(n=5284)$ in the south-eastern county of Blaenau Gwent (Welsh Government 2020). In Welsh-dominant areas, the language may still be used as a community language, which increases the amount of Welsh to which children are exposed, whereas, in areas where Welsh is spoken by a minority, exposure may be restricted to caregivers or 'more narrowly drawn social networks' (Coupland and Ball 1989, p. 10).

The establishment of Welsh-medium education in the twentieth century has proved popular as both first language education for children from Welsh-speaking homes and as immersion education for children with non-Welsh-speaking parents. In western areas, where Welsh is used as a community language, especially in north-west Wales, the majority of schools teach most subjects in Welsh, and only a minority of children come from nonWelsh-speaking homes. In eastern areas, parents may choose English-medium or Welshmedium education for their child. Welsh-medium education in eastern areas has proven a popular choice in areas where both English- and Welsh-medium schools exist (see Hodges 2012). Consequently, the majority of children in Welsh-medium schools in eastern areas come from English monolingual homes.

Welsh-English minority language bilingualism is complicated by two sets of intertwined dichotomies, which makes the situation inherently interesting for a study of language variation. Firstly, there is a distinction between the western heartland and other anglicised areas. This results in a group of speakers for whom Welsh is the main community language and a group for whom Welsh is arguably limited to certain domains or interlocutors. Secondly, there is a group of speakers who acquired Welsh in the home and a group who acquired Welsh through Welsh-medium education. Consequently, there are bilingual speakers who have different experiences of acquiring their languages. These groups are intertwined because there are increasing numbers of speakers in the heartland areas who speak English at home, and there has always been a proportion of the population in eastern areas who speak Welsh at home. Both having Welsh as a home language and 
living in a community where over $60 \%$ of the population speak the language are two factors that have been shown to influence daily use of Welsh (e.g., Jones 2008).

\subsection{Phonological Transfer and Cross-Linguistic Phonetic Interactions in the Speech of Welsh-English Bilinguals}

A number of accounts of Welsh English differentiate between accents based on the perceived influence of Welsh (see Durham and Morris 2016, pp. 14-16 for an overview). These differences are accounted for either by a substratum influence of Welsh (Wells 1982, p. 377) or synchronic transfer from Welsh to English in areas where most of the population speak Welsh (Awbery 1997, p. 88). Until recently, however, there have been few attempts to examine synchronic transfer in the speech of Welsh-English bilinguals.

Using the same dataset as the present study, Morris (2017) examined /1/-darkening in the Welsh and English of bilinguals and the extent to which there were cross-linguistic differences in the production of $/ 1 /$. The results of the statistical modelling showed that female speakers were more likely to differentiate between English and Welsh when producing /1/ in the onset position. A more cursory glance at the data revealed that it was the female speakers in the majority Welsh-speaking town of Caernarfon who showed the greatest differences between Welsh and English compared to the north-eastern town of Mold, where the majority of the population do not speak Welsh (Morris 2017, p. 200).

More recently, and again using the same dataset, Morris (forthcoming) investigated the extent to which there are cross-linguistic differences as well as linguistic and social influences, on four measures of Fundamental Frequency Range (minimum F0, maximum F0, mean F0, and the difference between the minimum and maximum F0). The results showed no cross-linguistic differences but clear areal differences between Caernarfon and Mold. Whereas gender was the most powerful predictor of variation across all measures, speakers' home language was also significant in Caernarfon. Those from Welsh-speaking families in Caernarfon produced a higher minimum, maximum, and mean F0 compared to those from English-speaking homes in the same area (once gender differences had been accounted for). Home language was the most powerful predictor of pitch span (the difference between minimum and maximum F0), with those from Welsh-speaking homes having a greater pitch span compared to those from English-speaking homes regardless of gender (see also Ordin and Mennen 2017 for a similar study which found cross-linguistic differences between Welsh and English in women's speech).

The home-language differences, which seem to be associated most strongly with Welsh-speaking areas (and where home language seems to be a more salient aspect of peer-group formation, see Morris 2014 and Section 3.2), have not been found in other areas. Mayr et al. (2017) examined the production of monophthongs in a community in south Wales. They compared bilingual data from male Welsh speakers from both Welsh- and English-speaking families and English data from male monolinguals. They found few cross-linguistic differences and no effect of home language in the bilinguals' data. There were also few differences between bilinguals and monolinguals in English. Similarly, Mennen et al. (2020) examined correlates of lexical stress in the same data and found no significant differences across most measures.

\section{3. /r/in Pre-Vocalic and Intervocalic Positions in Welsh and Welsh English}

Descriptions of / $\mathrm{r} /$ in both Welsh and Welsh English tend to be provided in general summaries of the phonology of both varieties or dialectological surveys (e.g., Parry 1977; Penhallurick 1991). In word-initial prevocalic and word-medial intervocalic positions, the voiced alveolar trill [r] is reported as being the most commonly realised variant of $/ \mathrm{r} /$ in Welsh, with partial devoicing occurring when it follows a preceding voiceless consonant. The voiced alveolar tap [r] is often used in word-medial intervocalic position in the northwest. The voiced uvular trill [R] or voiced uvular fricative $[\mathrm{s}]$ is a dialectal feature of the Bala area of Gwynedd (the county to which Caernarfon belongs), though there is no mention of the uvular variants in the speech of Caernarfon. The voiced alveolar approximant $[x]$ may appear in the clusters / tr/ and /dr/ and, according to Jones (1984, pp. 49-50), is 
an idiosyncratic feature for some speakers. The approximant is noted as being a dialectal feature of east Powys only (an area in Mid-Wales which borders England; Davies 1971).

The trilled and tapped variants of / $\mathrm{r} /$ are cited as being a feature of English for WelshEnglish bilinguals, and, in particular, in the speech of those living in the north-west (Wilson 2014). Elsewhere, it is assumed that it is the approximant that tends to occur in Welsh English (Penhallurick 1991, p. 132). In their investigation of the extent to which both Welshand non-Welsh-speaking people in Wales are able to differentiate between the English of bilingual and monolingual speakers, Mayr et al. (2020) asked participants to listen to extracts of English produced by Welsh-English bilinguals and English monolinguals from the same area. They found that the 'rolled $r^{\prime}$ was the most-cited feature that was associated with bilinguals' English (Mayr et al. 2020, p. 754). In a subsequent linguistic analysis of the extracts, they found a significant difference between monolingual and bilingual speakers, with bilingual speakers (all of whom came from Welsh-speaking homes) producing significantly more trills and taps than monolinguals (Mayr et al. 2020, p. 758).

\subsection{Research Questions}

The work outlined thus far suggests that there has been little variationist research which examines phonological transfer in the speech of Welsh-English bilinguals. In English, previous dialectological work indicates that the trill and tap are often produced in the speech of those from areas where Welsh is widely spoken by the local population (e.g., Penhallurick 1991). In Welsh, it appears that the alveolar approximant might appear in certain consonant clusters (Jones 1984, pp. 49-50), and there is limited evidence that the approximant might be a feature of some varieties closer to the border with England (Davies 1971).

The extent to which / $\mathrm{r} /$ varies in the two languages of Welsh speakers remains to be seen. Specifically, there has been hitherto no attempt to consider the role of linguistic and extra-linguistic factors on / $\mathrm{r} /$ variation in speakers' bilingual repertoires. As outlined previously, the consideration of phonological transfer through a variationist lens seems especially important in the Welsh context given the changes to the demographic profile of Welsh speakers in different areas across Wales. The study, therefore, aims to address the following research questions:

1. Is there evidence for phonological transfer in the production of $/ \mathrm{r} /$ in Welsh-English bilinguals' speech?

2. To what extent do linguistic and extra-linguistic factors influence the production of /r/ in English and Welsh?

3. To what extent are there differences in the patterning of variation between two communities where community dynamics and the use of Welsh differ?

\section{Materials and Methods}

Sociolinguistic interview and wordlist data in both Welsh and English were collected from 32 Welsh-English bilinguals aged 16-18 years old from north Wales. The area defined as north Wales for the purposes of this study included the counties of the Isle of Anglesey, Gwynedd, and Conwy County Borough to the west, and Denbighshire, Flintshire, and Wrexham County Borough to the east (population: 698, 400, see Welsh Government 2020). The remainder of this section outlines the communities, speakers, and methods in more detail.

\subsection{Communities}

The study included data collected from the areas around Caernarfon (Gwynedd) in north-west Wales and Mold (Flintshire) in north-east Wales as part of a wider project (Morris 2013). Both Caernarfon and Mold have comparable populations (around 10,000 people) and are so-called 'anchor towns' for outlying villages. There are, however, clear demographic and accentual differences between the two areas (see Morris 2017, for an overview of the accentual differences). 
The most relevant demographic difference between the two areas lies in the percentage of Welsh speakers. In Caernarfon and the surrounding area, $83.9 \%$ of the population are reported as being able to speak Welsh compared to $22.18 \%$ of the population in Mold (Welsh Government 2012). Consequently, Welsh can be viewed as more of a community language in Caernarfon, used as the main language interaction among most residents, whereas the use of Welsh in Mold is arguably much more restricted to Welsh-speaking social networks and certain community organisations.

\subsection{Speakers}

A total of 32 Welsh-English bilingual speakers were recruited from local education providers, where most of the speakers' subjects were delivered in Welsh. Speakers were aged between 16 and 18 at the time of data collection and had also been born in the wider local area (or moved to the area during infancy). Despite coming from the wider local area, speakers stated that either Caernarfon or Mold was the town with which they most closely identified. All participants self-identified as white and either Welsh, British, or both.

The sample for the study was stratified equally by area (Caernarfon or Mold), home language (Welsh or English), and gender (female or male). All speakers had either acquired Welsh at home and/or had received all of their education through the medium of Welsh. All students indicated either a male or female gender identity. Table 1 shows the sample for the current study.

Table 1. The sample.

\begin{tabular}{ccccc}
\hline & \multicolumn{2}{c}{ Caernarfon } & \multicolumn{2}{c}{ Mold } \\
\cline { 2 - 6 } & Male Speakers & Female Speakers & Male Speakers & Female Speakers \\
\hline Welsh at home & 4 & 4 & 4 & 4 \\
\hline English at home & 4 & 4 & 4 & 4 \\
\hline
\end{tabular}

The inclusion of a binary distinction between Welsh and English home languages is problematic, especially as no observations were made of language use in situ. This decision was taken, however, in light of the aims of the study to examine broad differences between those who acquired Welsh via parental transmission and those who acquired Welsh through education. The sample in the current study contained speakers who either had two Welshspeaking parents (or were being raised by a Welsh-speaking single parent) who used Welsh with their children or had non-Welsh-speaking parents with whom they spoke in English. There were no mixed-language households or speakers of other languages in the current sample.

Unlike in some similar linguistic contexts (see Tomé Lourido and Evans 2021), the speakers in this study were not aware of the term 'new speakers', and those from nonWelsh-speaking homes would not identify as such. The results of the written questionnaire, sociolinguistic interview, and my own observations indicated differences between language use and the salience of linguistic background among peers (see Morris 2014). While overt attitudes towards Welsh were generally positive, for instance, certain negative opinions were expressed by some speakers from English-speaking homes in Caernarfon. Such negative attitudes were related to either the speakers' own perceived ability in Welsh or Welsh language policy. Extracts (1) and (2) below show examples from the English sociolinguistic interviews of these overt attitudes from two different speakers from Englishspeaking homes in Caernarfon.

1. I think I can't [speak Welsh] though 'cause I remember the school was quite bitchy 'cause I was in primary school they used to start on me for it a lot for not being able to say it properly. 'Cause I was like one of the better performing kids in my year for everything apart from reading Welsh ... and that was really embarrassing and I think that's why I don't like it. I got good [grades] in the GCSEs, like I got Bs and stuff but I just don't like it [CEF2]. 
2. When I'm working... I get a lot of people coming to us saying we need to do more signs in Welsh. It's unnecessary [CEM3].

In Caernarfon, home language tended to be a primary indicator of peer-group membership (although certain individuals floated between friendship groups, see also Musk 2006), and it was common to hear those from English-speaking families speak English to those from Welsh-speaking families and receive a reply in Welsh (and vice versa, see (Gafaranga and Calvo 2001) for a similar finding in Catalonia).

The situation among the bilinguals in Mold was much different. Overt attitudes to Welsh were positive regardless of home-language background ${ }^{1}$, and language was rarely discussed in the sociolinguistic interviews. It became apparent, at least among the wider peer groups, that English was the main language of interaction and Welsh was reserved for educational contexts. This had been long-established, with one speaker from a Welshspeaking home commenting in the Welsh sociolinguistic interview that she had switched to using English with her friends at the beginning of secondary school (some six years previous) because of comments from her wider peer group (author's translation):

3. I used to speak Welsh with my friends (from primary school) and then I remember there was someone who used to call me swot for speaking Welsh and I felt really upset ... I still speak Welsh with my best friend but it's English that we speak (with other people) really [MWF1].

\subsection{Procedure}

Data were collected in a quiet room on school premises by the author, who is a Welsh-English bilingual from north Wales. During the first session, speakers completed a sociolinguistic interview and wordlist task in Welsh. Another sociolinguistic interview and wordlist, held in English, took place the following day. Interview modules were devised which aimed to elicit informal speech. The topics included in the Welsh interview were (1) childhood, (2) family, and (3) travelling. In the English interviews, speakers were asked questions regarding (1) their experiences of school, (2) the local area, and (3) their leisure activities. Each interview lasted for around 35 minutes.

\subsection{Data Coding and Analysis}

\subsubsection{Data Coding}

Up to 50 tokens of $/ \mathrm{r} /$ in prevocalic and intervocalic positions were extracted from each speaker's interview data (up to 25 tokens in each language). Only tokens that occurred following the first ten minutes of the interview were extracted, and only three instances of each word were included $(n=1577)$. A further 46 tokens were extracted from the wordlist data, although there were 57 instances of repetitions, which were also included in the analysis $(n=1529)$. Table 2 shows the number of tokens included in the analysis for each language by speaker area, gender, and home language.

Table 2. Number of tokens included in the analysis of $/ \mathrm{r} /$ in prevocalic and intervocalic positions $(\mathrm{EHL}=$ English home language, WHL = Welsh home language $)$.

\begin{tabular}{cccccccccc}
\hline & \multicolumn{4}{c}{ Mold } & \multicolumn{5}{c}{ Caernarfon } \\
\cline { 2 - 10 } & Female Speakers & \multicolumn{2}{c}{ Male Speakers } & Female Speakers & Male Speakers & Total \\
\cline { 2 - 10 } & EHL & WHL & EHL & WHL & EHL & WHL & EHL & WHL \\
\hline English & 189 & 196 & 197 & 194 & 196 & 182 & 190 & 196 & 1540 \\
\hline Welsh & 188 & 182 & 197 & 197 & 184 & 230 & 188 & 200 & 1566 \\
\hline Total & 377 & 378 & 394 & 391 & 380 & 412 & 378 & 396 & 3106 \\
\hline
\end{tabular}

1 As one reviewer pointed out, attitudes towards the language may differ among the monolingual population of Mold. 
Tokens were coded auditorily by the author, though each token was checked acoustically in Praat (Boersma and Weenink 2021) before a final decision was made (e.g., Chand 2010). Table 3 details the acoustic cues used for the identification of / $\mathrm{r} /$ variants:

Table 3. Acoustic cues used for the identification of /r/ variants.

\begin{tabular}{cl}
\hline Variant & \multicolumn{1}{c}{ Acoustic Cues } \\
\hline$[x]$ & $\begin{array}{l}\text { Decrease in the distance between F2 and F3, caused by lowering F3 and increasing } \\
\text { F2 out of the vowel accompanied by a decrease in amplitude (Ladefoged 2003, } \\
\text { p. 149). }\end{array}$ \\
\hline$[r] /[\mathrm{r}]$ & $\begin{array}{l}\text { Decrease in glottal energy at the end of the vowel, shown on the spectrogram as a } \\
\text { decrease in amplitude and loss of formant structure, followed by a single contact for } \\
{[r] \text { and two or more contacts for }[\mathrm{r}] \text { (Jones 2009). }}\end{array}$ \\
\hline
\end{tabular}

Each token was categorised as approximant, tap, trill, uvular fricative, or zero realisations. A total of $0.74 \%$ of tokens contained no audible production of $/ \mathrm{r} /$ (all in syllable onset position) and were omitted from the subsequent statistical analysis $(n=23)$. A ternary distinction was made between voiced, partially devoiced, and devoiced productions, but an analysis of voicing was not included in the subsequent analysis.

A sample of 320 tokens (10.30\% of the total number of tokens) was re-checked by the author. Ten interview tokens from each speaker were extracted and re-coded blindly following the same procedure, as outlined above (auditory coding and acoustic checking). The same decision was reached on the second round of coding for 317 of the tokens that yielded an agreement rate of $99.06 \%$. In the case of the three tokens, about which there was doubt, the original coding was retained.

\subsubsection{Statistical Analysis}

The statistical analysis of the / $\mathrm{r} /$ data was conducted using mixed-effects logistic regression analyses. All statistical modelling was carried out using the lme4 (Bates Douglas et al. 2015) and lmerTest (Kuznetsova Alexandra and Christensen 2017) packages for R ( $R$ Core Team 2020). Mixed-effects modelling allows the researcher to distinguish between fixed and random effects (Baayen 2009, p. 241). Fixed effects (e.g., Gender) are those factors that are replicable in further studies, whereas random effects (such as speaker and word) are sampled randomly (Baayen 2009, p. 241). By including speaker and word as random effects, the modelling is able to account for inter-speaker or inter-item variation when predicting which factors influence variation (Johnson 2009, p. 365).

In order to make comparisons between areas, separate models were intended to be conducted on the Mold and Caernarfon datasets, which included language as a fixed effect. For Mold, this was not possible as there was no variation in English, and modelling was undertaken on the Welsh data only. For Caernarfon, I provide the final model based on the Welsh and English data in Appendix A and present the models for English and Welsh separately in order to aid the interpretation of the interactions between language and social factors. Table 4 shows the factors included in the models. Interactions were also included in the models and are reported in Section 4.

Model selection proceeded as follows. Firstly, the model included the maximal random effects structure. Secondly, the random effects structure was iteratively simplified until the model converged (Baranowski and Turton 2020; Bates Douglas et al. 2015). The example below shows the $\mathrm{R}$ code for the Mold Welsh model containing the maximal random effects structure:

VARIANT HOME LANGUAGE $(\mathrm{HL})+$ TASK + STRESS + GENDER + CONTEXT + SYLLABLES + HL:TASK + HL:GENDER + GENDER:TASK + CONTEXT:STRESS + $(1$ + TASK + CONTEXT + STRESS + CONTEXT:STRESS I SPEAKER $)+(1$ I WORD $)$ 
The most complex model tested, shown above, included by-speaker random slopes for task, context, stress, and interaction of context and stress. The final models, reported in Section 4 below, contained speaker and word as random effects with no random slopes.

Table 4. Factors included in the statistical analysis of / $\mathrm{r}$ / variation (speaker and word included in all final models as random effects).

\begin{tabular}{|c|c|}
\hline Factor & Levels (Bold = Baseline) \\
\hline \multicolumn{2}{|c|}{ Dependent Variable } \\
\hline Variant & $\begin{array}{c}\text { Approximant } \\
\text { Other }\end{array}$ \\
\hline \multicolumn{2}{|c|}{ Independent Variables } \\
\hline Language & $\begin{array}{l}\text { English } \\
\text { Welsh }\end{array}$ \\
\hline Gender & $\begin{array}{c}\text { Female } \\
\text { Male }\end{array}$ \\
\hline Home Language & $\begin{array}{l}\text { English } \\
\text { Welsh }\end{array}$ \\
\hline Task & $\begin{array}{c}\text { Interview } \\
\text { Wordlist }\end{array}$ \\
\hline Phonological Context & $\begin{array}{l}\mathbf{V}_{-} \mathbf{V} \\
\#_{-} \mathrm{V} \\
\mathrm{C}_{-} \mathrm{V}\end{array}$ \\
\hline Syllable Type & $\begin{array}{l}\text { Monosyllabic } \\
\text { Polysyllabic }\end{array}$ \\
\hline Syllable stress & $\begin{array}{c}\text { Stressed } \\
\text { Unstressed }\end{array}$ \\
\hline
\end{tabular}

The individual results tables show the fixed factors (independent variables), which were significant predictors of $/ \mathrm{r} /$ variation and coefficients $(\beta)$, z-values, and $p$-values for the levels associated with each factor. Taking into consideration the random factors (see above), these coefficients represent a deviation from the baseline (see Table 4 for the levels of each factor taken as the baseline). A positive significant coefficient suggests that the named factor level was more likely to influence the production of the approximant than the baseline factor level. Similarly, a negative significant coefficient indicates that the named factor level was less likely to result in the production of the approximant than the baseline factor level.

\section{Results}

The presentation of the results proceeds as follows. Firstly, descriptive statistics of the overall frequency of tokens in each language are provided. This gives an overview of the results for reference and also establishes the extent to which transfer occurs between English and Welsh in these data. Secondly, the results of the mixed-effects modelling are described for (1) Mold and (2) Caernarfon. In both areas, the English-language subsets are presented first and then are followed by the Welsh-language subsets.

\subsection{Overall Frequency}

Looking at the dataset on the whole, excluding the zero realisations, it is clear that the overwhelming majority of tokens were realised as approximants. In total, $79.43 \%$ of tokens were produced as approximants $(n=2497)$. Of the non-approximant tokens, $11.24 \%$ were produced as taps $(n=349), 6.67 \%$ were produced as trills $(n=207)$, and $0.97 \%$ were produced as uvular fricatives $(n=30)$. Table 5 shows the percentage and number of tokens by language. 
Table 5. Percentage and number of /r/ variants in the English and Welsh subsets $(n=3083)$.

\begin{tabular}{cccccc}
\hline \multirow{2}{*}{ Variant } & \multicolumn{2}{c}{$\%$} & \multicolumn{3}{c}{$\boldsymbol{~}$} \\
\cline { 2 - 6 } & English & Welsh & English & Welsh & Total \\
\hline Uvular fricative & 0 & 1.93 & 0 & 30 & 30 \\
\hline Trill & 4.12 & 9.27 & 63 & 144 & 207 \\
\hline Tap & 5.16 & 17.39 & 79 & 270 & 349 \\
\hline Approximant & 90.72 & 71.41 & 1388 & 1109 & 2497 \\
\hline Total & - & - & 1530 & 1553 & 3083 \\
\hline
\end{tabular}

Before proceeding to the statistical analysis of the Mold and Caernarfon datasets, it is worth paying attention to the appearance of the uvular fricatives in the data. The uvular fricatives were found in the Welsh of one speaker from the Mold area. Despite not being expected in the areas under discussion (see Section 2.3), further questioning of the speaker revealed family connections to the Bala area, where uvular variants have been previously reported.

\subsection{Mold Dataset}

As stated in Section 3.4.2, no statistical modelling was undertaken on the entire Mold dataset as there was no variation in the English-language data (see Section 4.2.1 below). Instead, the data were divided into English-language and Welsh-language subsets.

\subsubsection{English-Language Subset}

Inspection of the data indicated that no variation was present in the English data and that all tokens were produced as approximants $(n=771)$.

\subsubsection{Welsh-Language Subset}

In the Mold Welsh-language subset $(n=754), 84.35 \%$ of tokens were realised as approximants $(n=636)$, compared to $8.75 \%$ of tokens realised as taps $(n=66)$ and $2.92 \%$ of trills $(n=22)$. One speaker produced instances of the uvular fricative associated with the Welsh of the north-western town of Bala and the surrounding area (see Section 4.1). These tokens accounted for 3.98\% of the total Mold Welsh-language subset $(n=30)$.

Table 6 shows the final model for the Mold Welsh-language subset (see Section 3.4.2). The model predicted the likelihood of the production of the approximant and contained speaker gender, speaker home language, task, phonological context, syllable type, and syllable stress as fixed effects. Interactions were included between home language and task, home language and gender, gender and task, and phonological context and syllable stress. Speaker and word were included as random effects ${ }^{2}$.

Firstly, the results for the Mold Welsh-language subset suggested that the realisation of the alveolar approximant in Welsh was less likely to occur in the speech of those from Welsh-speaking homes $(\beta=-3.735, z=-2.711, p=0.007)$. Of the Welsh tokens produced by those from Welsh-speaking homes, $73.85 \%$ were approximants $(n=274)$ compared to $94.52 \%$ of tokens produced by speakers from English-speaking homes $(n=362)$.

Secondly, the results also suggested that the alveolar approximant was less likely to occur in the wordlist task than in the interview data $(\beta=-1.385, z=-2.016, p=0.044)$. Figure 1 shows the distribution of variants in the interview and wordlist tasks. Of the tokens produced during the sociolinguistic interview, $90.78 \%$ were approximants $(n=394)$ compared to $75.63 \%$ of tokens in the wordlist data $(n=242)$.

2 R code: VARIANT $\sim$ HOME LANGUAGE $($ HL) + TASK + STRESS + GENDER + CONTEXT + SYLLABLES + HL:TASK + GENDER:HL + GENDER:TASK + CONTEXT:STRESS + (1 I SPEAKER $)+(1$ I WORD $)$ 
Table 6. Regression coefficients with $z$ - and $p$-values for the final model predicting the production of the alveolar approximant in the Mold Welsh-language subset $(n=754)$. Positive estimates indicate an increased likelihood of the alveolar approximant. $\mathrm{AIC}=473.6$.

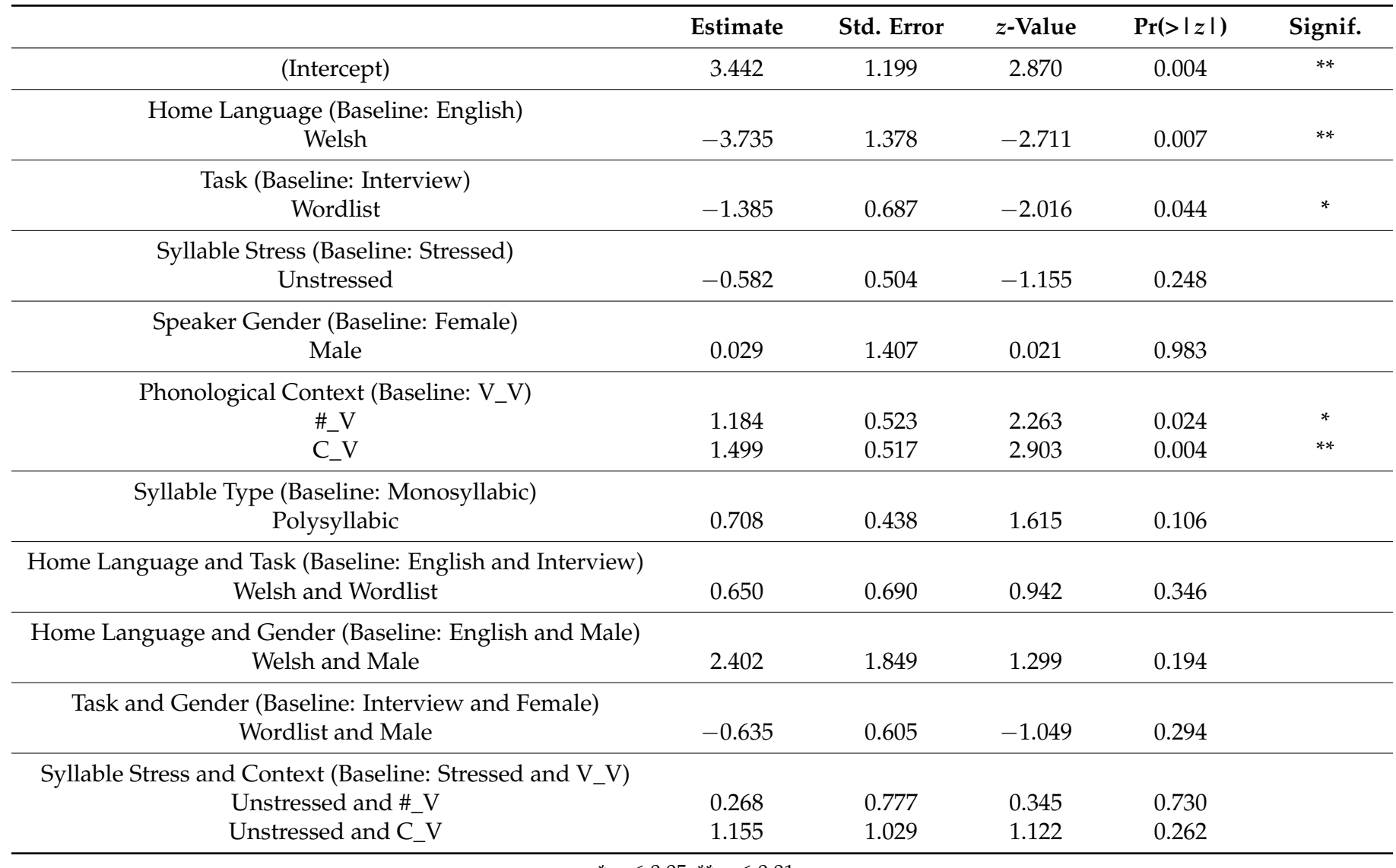

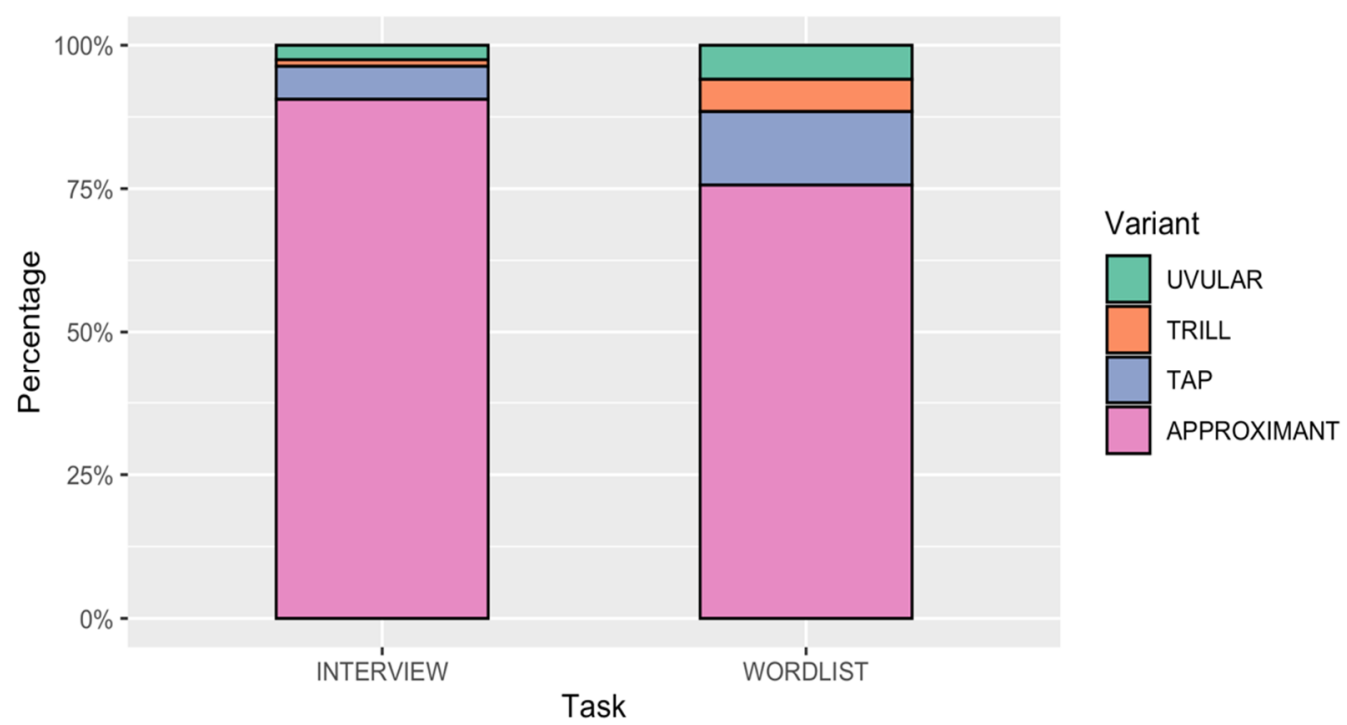

Figure 1. Distribution of /r/ variants in the Mold Welsh-language subset by task $(n=754)$.

Finally, phonological context was shown to be a significant predictor of variation in the Mold Welsh-language subset. The alveolar approximant was more likely to occur in C_V $(\beta=1.499, z=2.903, p=0.004)$ and \#_V contexts $(\beta=1.184, z=2.263, p=0.024)$ compared to intervocalically $\left(\mathrm{V}_{-} \mathrm{V}\right)$. 


\subsection{Caernarfon Dataset}

As stated in Section 3.4.2, initial statistical modelling was undertaken on the whole Caernarfon dataset and included language as a fixed effect (as well as a number of interactions between language and social factors). The results of this modelling are shown in Table A1 in Appendix A. The remainder of this section presents the modelling on the English- and Welsh-language subsets separately.

\subsubsection{English-Language Subset}

In the Caernarfon English-language subset $(n=759), 81.29 \%$ of tokens were produced as approximants $(n=617)$, compared to $10.41 \%$ of tokens which were produced as taps $(n=79)$ and $8.3 \%$ of tokens produced as trills $(n=63)$.

Table 7 shows the final model for the Caernarfon English-language subset (see Section 3.4.2). The model predicted the likelihood of the production of the approximant and contained speaker gender, speaker home language, task, phonological context, syllable type, and syllable stress as fixed effects. Interactions were included between home language and task, gender and task, and phonological context and syllable stress. The interaction between home language and gender was removed as there was no variation in the data of male speakers from English-speaking homes. Speaker and word were included as random effects ${ }^{3}$.

Table 7. Regression coefficients with $z$ - and $p$-values for the final model predicting the production of the alveolar approximant in the Caernarfon English-language subset $(n=759)$. Positive estimates indicate an increased likelihood of the alveolar approximant. AIC $=471.5$.

\begin{tabular}{|c|c|c|c|c|c|}
\hline & Estimate & Std. Error & $z$-Value & $\operatorname{Pr}(>|z|)$ & Signif. \\
\hline (Intercept) & 6.085 & 1.557 & 3.909 & $<0.001$ & $* * *$ \\
\hline \multicolumn{6}{|c|}{ Home Language (Baseline $=$ English) } \\
\hline Welsh & -4.968 & 1.669 & -2.978 & 0.003 & $* *$ \\
\hline \multicolumn{6}{|l|}{ Task $($ Baseline $=$ Interview $)$} \\
\hline Wordlist & -2.373 & 0.783 & -3.030 & 0.002 & $* *$ \\
\hline \multicolumn{6}{|c|}{ Syllable Stress $($ Baseline $=$ Stressed $)$} \\
\hline Unstressed & 1.247 & 1.056 & 1.180 & 0.238 & \\
\hline \multicolumn{6}{|c|}{ Speaker Gender (Baseline = Female) } \\
\hline Male & 1.630 & 1.462 & 1.115 & 0.265 & \\
\hline \multicolumn{6}{|c|}{ Phonological Context (Baseline $=$ V_V) } \\
\hline \#_V & 0.359 & 0.468 & 0.766 & 0.444 & \\
\hline $\mathrm{C}_{-}^{-} \mathrm{V}$ & 0.521 & 0.592 & 0.881 & 0.379 & \\
\hline \multicolumn{6}{|c|}{ Syllable Type (Baseline $=$ Monosyllabic) } \\
\hline Polysyllabic & -0.051 & 0.386 & -0.131 & 0.896 & \\
\hline \multicolumn{6}{|c|}{$\begin{array}{c}\text { Home Language and Task }(\text { Baseline }=\text { English and } \\
\text { Interview) }\end{array}$} \\
\hline Welsh and Wordlist & 0.329 & 0.852 & 0.386 & 0.700 & \\
\hline \multicolumn{6}{|c|}{ Task and Gender (Baseline = Interview and Female) } \\
\hline Wordlist and Male & 1.896 & 0.636 & 2.980 & 0.003 & ** \\
\hline \multicolumn{6}{|c|}{ Syllable Stress and Context $($ Baseline $=$ Stressed and V_V) } \\
\hline Unstressed and \#_V & -1.901 & 1.248 & -1.523 & 0.128 & \\
\hline Unstressed and C_V & -1.506 & 1.446 & -1.042 & 0.298 & \\
\hline
\end{tabular}

$$
{ }^{* *} p \leq 0.01, * * * p \leq 0.001
$$

3 R code: VARIANT $\sim$ HOME LANGUAGE $($ HL) + TASK + STRESS + GENDER + CONTEXT + SYLLABLES + HL:TASK + GENDER:TASK + CONTEXT:STRESS + (1 I SPEAKER $)+(1$ I WORD $)$ 
The results of the statistical modelling, shown in Table 7, suggested that those from Welsh-speaking homes were less likely to produce the alveolar approximant in the Caernarfon English-language subset compared to those from English-speaking homes $(\beta=-4.968$, $z=-2.978, p=0.003)$. Of the English tokens produced by those from Welsh-speaking homes in Caernarfon, $68.53 \%$ were approximants $(n=257)$, compared to $93.75 \%$ of tokens produced by speakers from English-speaking homes $(n=362)$.

Although there was a significant main effect for $\operatorname{task}(\beta=-2.373, z=-3.030, p=0.002)$, the model also showed a significant interaction between speaker gender and task $(\beta=1.896$, $z=2.980, p=0.003$ ), which requires further examination. Figure 2 shows the percentage of variants produced in the Caernarfon English-language subset by task and speaker gender. The figure shows that $87.04 \%$ of the tokens produced by female speakers during the interview task were approximants $(n=141)$ compared to $61.11 \%$ of the tokens produced during the wordlist task $(n=132)$. In the male speakers' data, $89.51 \%$ of the tokens produced during the interview task were approximants $(n=128)$ compared to $90.38 \%$ of the tokens produced during the wordlist task $(n=216)$.

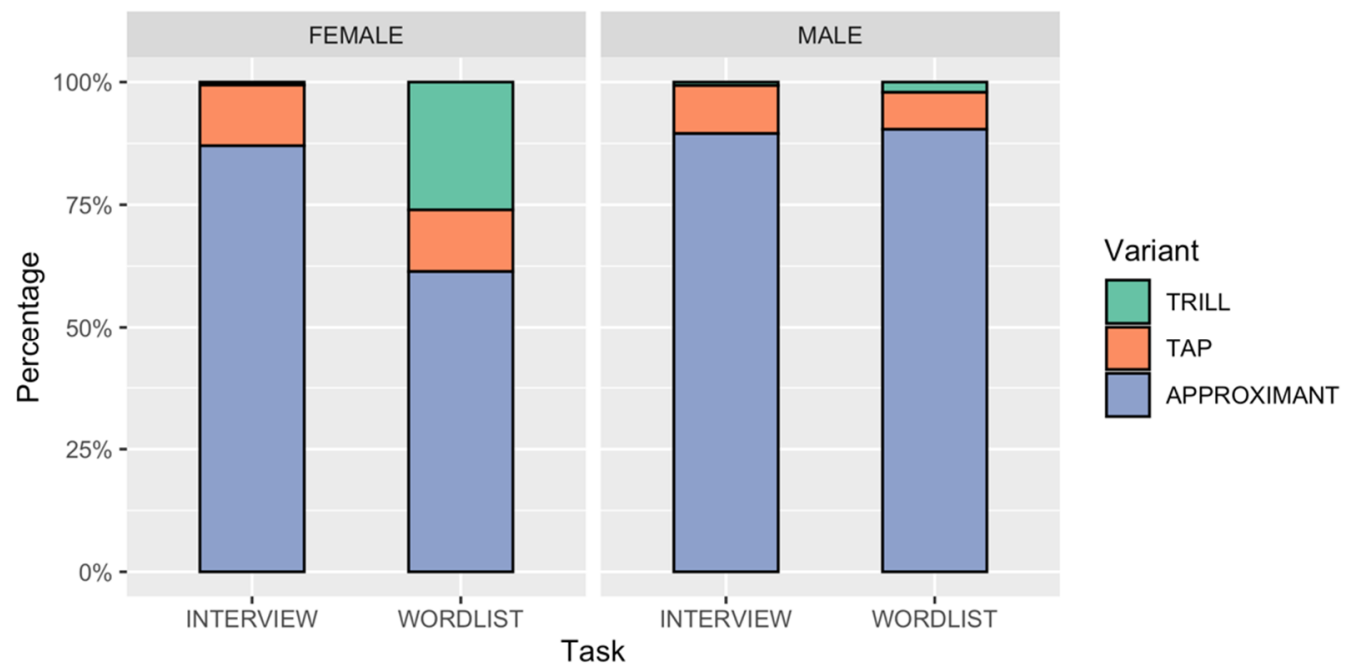

Figure 2. Distribution of $/ \mathrm{r} /$ variants in the Caernarfon English-language subset by speaker gender and task $(n=759)$.

To summarise, the alveolar approximant was less likely to occur in the speech of those from Welsh-speaking homes in the Caernarfon English-language subset. A significant interaction between speaker gender and task was also found, with female speakers being more likely to produce fewer approximant tokens in the wordlist task when compared to the interview task. The following section examines the Caernarfon Welsh-language subset.

\subsubsection{Welsh-Language Subset}

In the Caernarfon Welsh-language subset $(n=799), 59.20 \%$ of tokens were realised as approximants $(n=473)$, compared to $25.53 \%$ of tokens realised as taps $(n=204)$ and $15.27 \%$ of tokens realised as trills $(n=122)$.

Table 8 shows the final model for the Caernarfon Welsh-language subset (see Section 3.4.2). The model predicted the likelihood of the production of the approximant and contained speaker gender, speaker home language, task, phonological context, syllable type, and syllable stress as fixed effects. Interactions were included between home language and task, home language and gender, gender and task, and phonological context and syllable stress. Speaker and word were included as random effects ${ }^{4}$.

4 R code: VARIANT HOME LANGUAGE $($ HL ) + TASK + STRESS + GENDER + CONTEXT + SYLLABLES + HL:TASK + GENDER:HL + GENDER:TASK + CONTEXT:STRESS + (1 ISPEAKER $)+(1$ I WORD $)$ 
Table 8. Regression coefficients with $z$ - and $p$-values for the final model predicting the production of the alveolar approximant in the Caernarfon Welsh-language subset $(n=799)$. Positive estimates indicate an increased likelihood of the alveolar approximant. $\mathrm{AIC}=876.4$.

\begin{tabular}{|c|c|c|c|c|c|}
\hline & Estimate & Std. Error & $z$-Value & $\operatorname{Pr}(>|z|)$ & Signif. \\
\hline (Intercept) & 0.390 & 0.632 & 0.617 & 0.537 & \\
\hline \multicolumn{6}{|c|}{ Home Language (Baseline = English) } \\
\hline Welsh & -0.189 & 0.585 & -0.323 & 0.746 & \\
\hline \multicolumn{6}{|l|}{ Task $($ Baseline $=$ Interview $)$} \\
\hline Wordlist & -1.164 & 0.397 & -2.930 & 0.003 & $* *$ \\
\hline \multicolumn{6}{|c|}{ Syllable Stress $($ Baseline $=$ Stressed) } \\
\hline Unstressed & -0.394 & 0.497 & -0.793 & 0.428 & \\
\hline \multicolumn{6}{|c|}{ Speaker Gender (Baseline = Female) } \\
\hline Male & 1.656 & 0.628 & 2.636 & 0.008 & $* *$ \\
\hline \multicolumn{6}{|c|}{ Phonological Context (Baseline $=$ V_V) } \\
\hline \#_V & 0.110 & 0.431 & 0.254 & 0.800 & \\
\hline$C_{-} \mathrm{V}$ & 0.882 & 0.428 & 2.059 & 0.039 & * \\
\hline \multicolumn{6}{|c|}{ Syllable Type (Baseline = Monosyllabic) } \\
\hline Polysyllabic & 0.099 & 0.380 & 0.259 & 0.795 & \\
\hline \multicolumn{6}{|c|}{$\begin{array}{l}\text { Home Language and Task }(\text { Baseline }=\text { English and } \\
\text { Interview) }\end{array}$} \\
\hline Welsh and Wordlist & -0.982 & 0.409 & -2.402 & 0.016 & * \\
\hline \multicolumn{6}{|c|}{ Home Language and Gender (Baseline = English and Male) } \\
\hline Welsh and Male & -1.517 & 0.819 & -1.852 & 0.064 & \\
\hline \multicolumn{6}{|c|}{ Task and Gender (Baseline = Interview and Female) } \\
\hline Wordlist and Male & 0.634 & 0.401 & 1.581 & 0.114 & \\
\hline \multicolumn{6}{|c|}{ Syllable Stress and Context $($ Baseline $=$ Stressed and V_V) } \\
\hline Unstressed and \#_V & 0.294 & 0.676 & 0.435 & 0.664 & \\
\hline Unstressed and C_V & 0.427 & 0.777 & 0.549 & 0.583 & \\
\hline
\end{tabular}

$$
{ }^{*} p \leq 0.05,{ }^{* *} p \leq 0.01 \text {. }
$$

The results for the Caernarfon Welsh-language subset indicated that the alveolar approximant in Welsh was more likely to occur in male speakers' speech $(\beta=1.656$, $z=2.636, p=0.008)$. Of the tokens produced by male speakers, $67.62 \%$ were approximants $(n=261)$. In the female speakers' data, $51.33 \%$ of tokens were produced as approximants $(n=212)$.

Although home language was not a significant predictor of the realisation of the alveolar approximant in the Caernarfon Welsh-language subset $(\beta=-0.189, z=-0.323$, $p=0.746)$, there was a significant interaction between home language and task $(\beta=-0.982$, $z=-2.402, p=0.016$ ). Those from Welsh-speaking homes were less likely to produce the alveolar approximant in the wordlist task than in the interview task compared to those from English-speaking homes. Figure 3 shows the distribution of variants in the interview and wordlist tasks by speaker home language.

In the Welsh data produced by speakers from Welsh-speaking homes in Caernarfon, $63.94 \%$ of tokens produced in the interview task were approximants $(n=172)$ compared to $25.16 \%$ of tokens produced during the wordlist task $(n=40)$. In the Welsh data obtained from those from English-speaking homes in Caernarfon, $78.34 \%$ of tokens in the interview task were produced as approximants $(n=170)$ compared to $59.09 \%$ of tokens in the wordlist task $(n=91)$.

Finally, the phonological context was found to be significant. The alveolar approximant was more likely to occur in $C_{-} V$ position $(\beta=0.882, z=2.059, p=0.039)$ than intervocalically. 


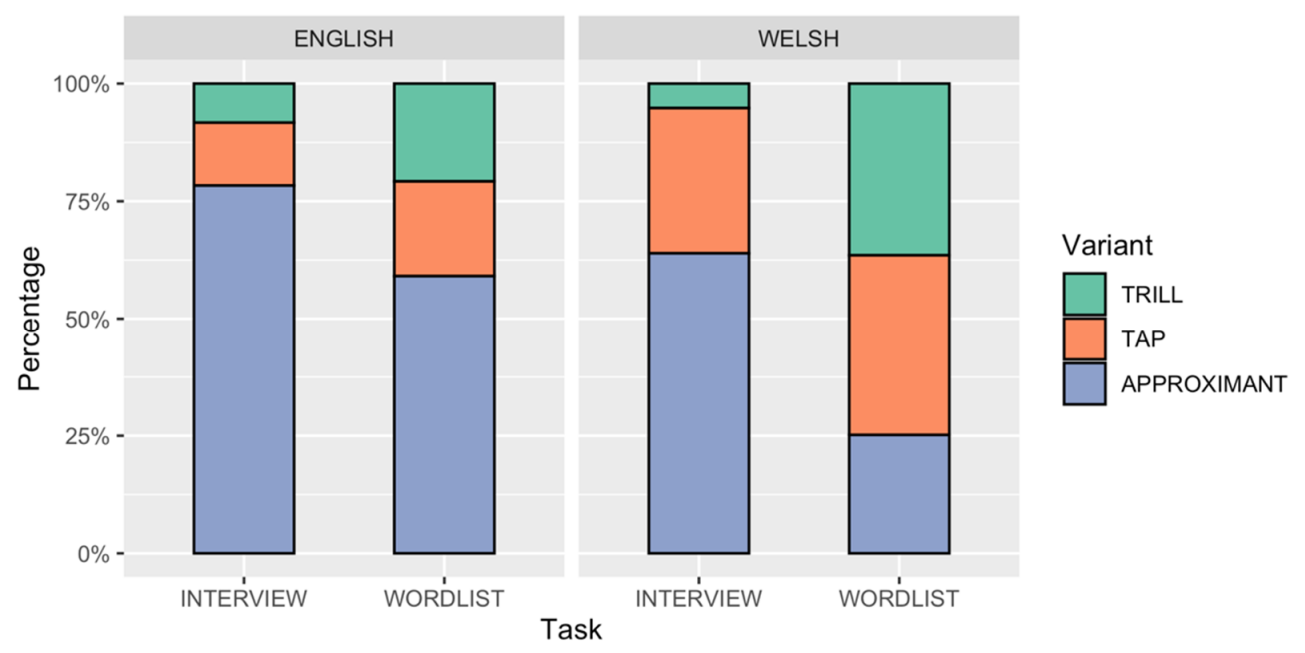

Figure 3. Distribution of /r/ variants in the Caernarfon Welsh-language subset by home language and task $(n=799)$.

\section{Discussion and Conclusions}

The study sought to examine (1) the variants of / $\mathrm{r} /$ present in the bilingual repertoire of Welsh-English bilinguals, (2) the linguistic and extra-linguistic factors which influence variation in both Welsh and English in two communities, and (3) the extent to which there were differences between two communities which differ sociolinguistically.

The alveolar approximant was the most common variant in the bilingual repertoire of most of the speakers included in this study. The Welsh variants (the trill, tap, and, in the case of one speaker, the uvular fricative) were wholly absent from the English data in Mold, although they appeared in variation with the approximant in Welsh. Although looking at the raw percentages showed that the vast majority of tokens in the Caernarfon English-language subset were produced as approximants $(80.76 \%$ compared to $58.98 \%$ in the Caernarfon Welsh-language subset), the mixed-effects modelling showed that there were social effects on variation in both languages, and, consequently, the cross-linguistic differences in Caernarfon were less clear.

The high frequency of the alveolar approximant in the Welsh data provides evidence for phonological transfer in the two areas and among both traditional and new speakers. This contradicts previous work on Welsh dialectology, which posits that the alveolar approximant is an idiosyncratic feature of Welsh or restricted to certain border areas (see Section 2.3). Both the descriptive and inferential statistics presented in Section 4 indicate that the appearance of the alveolar approximant in Welsh is not ephemeral 'interference' in the speech of Welsh-English bilinguals in both communities and that the alveolar approximant in Welsh is a consistent transfer feature which is subject to social constraints.

It is not possible to comment on the extent to which the production of the alveolar approximant in Welsh constitutes language change in progress (to the extent to which this is possible in certain revitalisation contexts see Nance 2015, p. 573). Further comparisons with older speakers in both areas would be needed to substantiate this claim. However, it is clear that there are linguistic and extra-linguistic factors that influence variation in both English and Welsh and that these factors pattern differently in the two communities under discussion. It is to these two points which I now turn.

The linguistic factors included in the analysis were not significant predictors of $/ \mathrm{r} /$ in the English of the two communities. In Welsh, the results in the two areas showed that the alveolar approximant was favoured in C_V contexts. This supports previous work in Welsh, which claims that the approximant is common in onset clusters (Jones 1984, pp. 59-60).

In work based on the same dataset analysed in the current study, Morris (2017) found no home-language differences for $/ 1 /$-darkening (a gradient phonetic feature). Home language was found to be significant in Caernarfon, however, for measures related to Fundamental Frequency Range (Morris, forthcoming). In other work, no home language differences were found in the production of monophthongs (Mayr et al. 2017) or lexical 
stress (Mennen et al. 2020) in either the Welsh or English of Carmarthenshire or in the production of high back vowels in Cardiff Welsh (Gruffydd, forthcoming). Previous work also showed that certain accentual cues in English helped listeners to differentiate between Welsh- and non-Welsh-speakers (Mayr et al. 2020) and that Welsh variants of /r/, as well as prosodic features, were markers of strongly Welsh-accented speech associated with Welsh-speaking areas (Penhallurick 1991; Wells 1982, p. 390; Wilson 2014; Mayr et al. 2020).

The results of the modelling indicate that those from English-speaking homes were more likely to produce the approximant in both Caernarfon and Mold Welsh. The significance of home language on this feature in Welsh was unsurprising in light of the varying degrees of exposure to Welsh each group had received. Home language tended to correlate with selfreported usage and ability in Welsh, which in turn were highly predictive of the role Welsh is likely to play in the life of an adolescent speaker (Musk 2006; Morris 2014). As was shown in Section 3.2, the importance of home language as a marker of identity among the speakers seemed to be more obvious in Caernarfon, where peer groups often used either Welsh or English. This could explain the more prominent home-language differences. In Mold, the role of home language was much more subtle, and my own observations were that those Welsh-speaking background were much more eager to 'fit in' with their peers from English-speaking homes. This could go some way to describe the lack of home-language differences in Mold English, but further ethnographic work would be needed to examine this further.

Task was a significant predictor of variation in Mold Welsh, and the results for Caernarfon showed a significant interaction between home language and task in Welsh. In Caernarfon Welsh, those from Welsh-speaking homes were more likely to style-shift and produce fewer approximant tokens in the wordlist tasks compared to those from English-speaking homes. The results for the Welsh data pointed towards stylistic variation, wherein speakers tended to produce more standard variants in more formal speech. The fact that speakers from English-speaking homes in Caernarfon were less likely to style-shift provided, in my opinion, more evidence that /r/ may have socio-indexical meaning in this area.

Gender differences were also found to operate independently of differences between the two home-language groups in Caernarfon. In the Caernarfon English-language subset, female speakers were more likely to style-shift and produce fewer approximant tokens in the wordlist task. In Welsh, they were also less likely to produce the alveolar approximant regardless of the task. Differences in patterns of style-shifting, and the production of standard variants between male and female speakers, are well-attested in variationist sociolinguistics (Kuznetsova Alexandra and Christensen 2001, p. 274), but generalisations across communities are also problematic (e.g., Eckert and McConnell-Ginet 1992). The fact that female speakers orient away from the alveolar approximant in both Welsh and English cannot be easily reconciled with the idea that women are more likely to orient towards standard norms. Instead, they appear to be more likely to produce the standard variant in their Welsh and style-shift towards a local norm and Welsh-accented speech in their English. Further work on the perception of /r/ in both varieties might shed further light on what social evaluations speakers hold with regard to this feature and whether such evaluations differ between Welsh and English.

The absence of the traditionally Welsh-language features from Mold English contributes to our understanding of the notion of language mode in bilingualism studies (e.g., Grosjean 1989), and, in particular, the notion that socio-psychological factors influence cross-linguistic interactions. I would argue that local accentual norms may be considered one such factor and that the young bilingual speakers in Mold tend to adhere to local norms among English monolinguals in their categorical use of the alveolar approximant. This differs from Caernarfon, where local norms are based on a majority population of bilingual speakers. Similar results were found in perception studies of Welsh English accents, where typically Welsh-influenced features are associated with areas with a high proportion of Welsh-English bilinguals (e.g., Williams et al. 1996).

The results indicate that there are clear differences between communities which can, to a certain extent, be explained by the sociolinguistic differences, which exist between Caernarfon and Mold and, more specifically, the peer groups included in the current study. 
Funding: This research was partly funded by the Johansson Scholarship, awarded by the School of Arts, Languages and Cultures, University of Manchester.

Institutional Review Board Statement: The study was conducted according to the guidelines of the Declaration of Helsinki, and approved by the Institutional Review Board (or Ethics Committee) of the School of Arts, Languages and Cultures, University of Manchester.

Informed Consent Statement: Informed consent was obtained from all subjects involved in the study.

Data Availability Statement: The data presented in this study are available on request from the author. The data are not publicly available due to confidentiality restrictions.

Acknowledgments: I would like to thank the anonymous reviewers for their insightful comments.

Conflicts of Interest: The author declares no conflict of interest.

\section{Appendix A}

Table A1. Regression coefficients with $z$ - and $p$-values for the final model predicting the production of the alveolar approximant in Caernarfon $(n=1558)$. Positive estimates indicate an increased likelihood of the alveolar approximant. AIC $=1350.7$.

\begin{tabular}{|c|c|c|c|c|c|}
\hline & Estimate & Std. Error & z-Value & $\operatorname{Pr}(>|z|)$ & Signif. \\
\hline (Intercept) & 3.189 & 0.733 & 4.348 & $<0.001$ & $* * *$ \\
\hline \multicolumn{6}{|c|}{ Language (Baseline: English) } \\
\hline Welsh & -2.418 & 0.432 & -5.593 & $<0.001$ & $* * *$ \\
\hline \multicolumn{6}{|c|}{ Home Language (Baseline: English) } \\
\hline Welsh & -1.932 & 0.821 & -2.355 & 0.019 & * \\
\hline \multicolumn{6}{|l|}{ Task (Baseline: Interview) } \\
\hline Wordlist & -0.986 & 0.431 & -2.287 & 0.022 & * \\
\hline \multicolumn{6}{|c|}{ Syllable Stress (Baseline: Stressed) } \\
\hline Unstressed & -0.077 & 0.245 & -0.312 & 0.755 & \\
\hline \multicolumn{6}{|c|}{ Speaker Gender (Baseline: Female) } \\
\hline Male & 2.464 & 0.891 & 2.764 & 0.006 & ** \\
\hline \multicolumn{6}{|c|}{ Phonological Context (Baseline: V_V) } \\
\hline \#_V & 0.152 & 0.263 & 0.575 & 0.565 & \\
\hline $\mathrm{C}_{-} \mathrm{V}$ & 0.660 & 0.308 & 2.142 & 0.032 & * \\
\hline \multicolumn{6}{|c|}{ Syllable Type (Baseline: Monosyllabic) } \\
\hline Polysyllabic & -0.081 & 0.263 & -0.309 & 0.757 & \\
\hline \multicolumn{6}{|c|}{ Home Language and Task (Baseline: English and Interview) } \\
\hline Welsh and Wordlist & -0.634 & 0.355 & -1.786 & 0.074 & \\
\hline \multicolumn{6}{|c|}{ Home Language and Gender (Baseline: English and Male) } \\
\hline Welsh and Male & -1.620 & 1.075 & -1.507 & 0.132 & \\
\hline \multicolumn{6}{|c|}{ Task and Gender (Baseline: Interview and Female) } \\
\hline Wordlist and Male & 1.095 & 0.334 & 3.278 & 0.001 & $* *$ \\
\hline \multicolumn{6}{|c|}{$\begin{array}{l}\text { Language and Home Language (Baseline: English and } \\
\text { English HL) }\end{array}$} \\
\hline Welsh and Welsh HL & 1.601 & 0.425 & 3.766 & $<0.001$ & $* * *$ \\
\hline \multicolumn{6}{|c|}{ Language and Gender (Baseline: English and Female) } \\
\hline Welsh and Male & 1.601 & 0.425 & 3.766 & $<0.001$ & $* * *$ \\
\hline \multicolumn{6}{|c|}{ Language and Task (Baseline: English and Interview) } \\
\hline Welsh and Wordlist & -0.755 & 0.414 & -1.825 & 0.068 & \\
\hline
\end{tabular}




\section{References}

Awbery, Gwenllian. 1997. The English language in Wales. In The Celtic Englishes. Edited by Hildegard L. C. Tristram. Heidelberg: Winter, pp. 86-99.

Baayen, Harald. 2009. Analyzing Linguistic Data: A Practical Introduction to Statistics Using R. Cambridge: Cambridge University Press.

Baranowski, Maciej, and Danielle Turton. 2020. TD-deletion in British English: New evidence for the long-lost morphological effect. Language Variation and Change 32: 1-23. [CrossRef]

Bates Douglas, Martin Mächler, Ben Bolker, and Steve Walker. 2015. Fitting Linear Mixed-Effects Models Using lme4. Journal of Statistical Software 67: 1-48.

Boersma, Paul, and David Weenink. 2021. Praat: Doing Phonetics by Computer [Computer Program]. Version 6.1.40. Available online: http:/ / www.praat.org/ (accessed on 21 March 2021).

Chand, Vineeta. 2010. Postvocalic (r) in urban Indian English. English World-Wide 31: 1-39. [CrossRef]

Coupland, Nikolas, and Martin J Ball. 1989. Welsh and English in contemporary Wales: Sociolinguistic issues. Contemporary Wales 3: $7-40$.

Davidson, Justin Spencer. 2015. Social Dynamics of Catalan-Spanish Contact in the Evolution of Catalonian Spanish. Ph.D. thesis, University of Illinois at Urbana-Champaign, Champaign, IL, USA.

Davies, Lyn. 1971. Linguistic interference in East Montgomeryshire. The Montgomeryshire Collections 62: 183-94.

Durham, Mercedes, and Jonathan Morris. 2016. An overview of sociolinguistics in Wales. In Sociolinguistics in Wales. Edited by Mercedes Durham and Jonathan Morris. London: Macmillan, pp. 3-28.

Eckert, Penelope, and Sally McConnell-Ginet. 1992. Think practically and look locally: Language and gender as community-based practice. Annual Review of Anthropology 21: 461-88. [CrossRef]

Gafaranga, Joseph, and Maria-Carme Torras i Calvo. 2001. Language versus medium in the study of bilingual conversation. International Journal of Bilingualism 5: 195-219. [CrossRef]

Gafter, Roey J., and Uri Horesh. 2020. Two languages, one variable? Pharyngeal realizations among Arabic-Hebrew bilinguals. Journal of Sociolinguistics 24: 369-87. [CrossRef]

Grosjean, François. 1989. Neurolinguists, beware! The bilingual is not two monolinguals in one person. Brain and Language 36: 3-15. [CrossRef]

Grosjean, François. 2001. The bilingual's language modes. In One Mind, Two Languages: Bilingual Language Processing. Edited by Janet Nicol. Oxford: Blackwell, pp. 1-22.

Gruffydd, Ianto. Forthcoming. Amrywio Ieithyddol Mewn Ysgol Gymraeg yng Nghaerdydd. Ph.D. thesis, Cardiff University, Cardiff, UK.

Hodges, Rhian Siân. 2012. Welsh-medium education and parental incentives-the case of the Rhymni Valley, Caerffili. International Journal of Bilingual Education and Bilingualism 15: 355-73. [CrossRef]

Johnson, Daniel Ezra. 2009. Getting off the GoldVarb standard: Introducing Rbrul for mixed-effects variable rule analysis. Language and Linguistics Compass 3: 359-83. [CrossRef]

Jones, Glyn E. 1984. The distinctive vowels and consonants of Welsh. In Welsh Phonology: Selected Readings. Edited by Martin J. Ball and Glyn E. Jones. Cardiff: University of Wales Press, pp. 40-64.

Jones, Hywel M. 2008. The changing social context of Welsh: A review of statistical trends. International Journal of Bilingual Education and Bilingualism 11: 541-57. [CrossRef]

Jones, Mark J. 2009. Patterns of variability in apical trills: An acoustic study of data from 19 languages. unpublished manuscript.

Kuznetsova Alexandra, Per B. Brockhoff, and Rune H. B. Christensen. 2017. lmerTest Package: Tests in Linear Mixed Effects Models. Journal of Statistical Software 82: 1-26. [CrossRef]

Kuznetsova Alexandra, Per B. Brockhoff, and Rune H. B. Christensen. 2001. Principles of Linguistic Change. Volume 2: Social Factors. Oxford: Blackwell.

Ladefoged, Peter. 2003. Phonetic Data Analysis: An Introduction to Fieldwork and Instrumental Techniques. Oxford: Blackwell.

Mayr, Robert, and Simona Montanari. 2015. Cross-linguistic interaction in trilingual phonological development: The role of the input in the acquisition of the voicing contrast. Journal of Child Language 42: 1006-35. [CrossRef] [PubMed]

Mayr, Robert, Jonathan Morris, Ineke Mennen, and Daniel Williams. 2017. Disentangling the effects of long-term language contact and individual bilingualism: The case of monophthongs in Welsh and English. International journal of bilingualism 21: 245-67. [CrossRef]

Mayr, Robert, Llian Roberts, and Jonathan Morris. 2020. Can you tell by their English if they can speak Welsh? Accent perception in a language contact situation. International Journal of Bilingualism 24: 740-66. [CrossRef]

Mennen, Ineke. 2004. Bi-directional interference in the intonation of Dutch speakers of Greek. Journal of Phonetics 32: 543-63. [CrossRef]

Mennen, Ineke, Niamh Kelly, Robert Mayr, and Jonathan Morris. 2020. The effects of home language and bilingualism on the realization of lexical stress in Welsh and Welsh English. Frontiers in Psychology 10: 3038. [CrossRef]

Mooney, Damien. 2019. Phonetic transfer in language contact: Evidence for equivalence classification in the mid-vowels of OccitanFrench bilinguals. International Phonetic Association. Journal of the International Phonetic Association 49: 53-85. [CrossRef]

Morris, Jonathan. 2013. Sociolinguistic Variation and Regional Minority Language Bilingualism: An Investigation of Welsh-English Bilinguals in North Wales. Ph.D. thesis, University of Manchester, Manchester, UK. 
Morris, Jonathan. 2014. The influence of social factors on minority language engagement amongst young people: An investigation of Welsh-English bilinguals in North Wales. International Journal of the Sociology of Language 2014: 65-89. [CrossRef]

Morris, Jonathan. 2017. Sociophonetic variation in a long-term language contact situation:/1/-darkening in Welsh-English bilingual speech. Journal of Sociolinguistics 21: 183-207. [CrossRef]

Morris, Jonathan. Forthcoming. Fundamental frequency range in the bilingual repertoire of traditional and new Welsh speakers. International Journal of Bilingualism.

Musk, Nigel. 2006. Performing Bilingualism in Wales with the Spotlight on Welsh: A Study of Language Policy and the Language Practices of Young People in Bilingual Education. Ph.D. thesis, Linköping University, Linköping, Sweden.

Nagy, Naomi. 2015. A sociolinguistic view of null subjects and VOT in Toronto heritage languages. Lingua 164: 309-27. [CrossRef]

Nance, Claire. 2013. Phonetic Variation, Sound Change, and Identity in Scottish Gaelic. Ph.D. thesis, University of Glasgow, Glasgow, Scotland.

Nance, Claire. 2015. 'New' Scottish Gaelic speakers in Glasgow: A phonetic study of language revitalisation. Language in Society 44: 553-79. [CrossRef]

Odlin, Terence. 1989. Language Transfer: Cross-Linguistic Influence in Language Learning. Cambridge: Cambridge University Press.

Ordin, Mikhail, and Ineke Mennen. 2017. Cross-linguistic differences in bilinguals' fundamental frequency ranges. Journal of Speech, Language, and Hearing Research 60: 1493-506. [CrossRef] [PubMed]

Parry, David. 1977. The Survey of Anglo-Welsh Dialects. Volume 1: The South-East. Swansea: University College Swansea.

Penhallurick, Robert J. 1991. The Anglo-Welsh dialects of north Wales. A survey of conservative rural spoken English in the counties of Gwynedd and Clwyd. Bamberger Beiträge zur Englischen Sprachwissenschaft 27.

Piske, Thorsten, Ian R. A. MacKay, and James E. Flege. 2001. Factors affecting degree of foreign accent in an L2: A review. Journal of Phonetics 29: 191-215. [CrossRef]

R Core Team. 2020. R: A Language and Environment for Statistical Computing. Vienna: R Foundation for Statistical Computing. Available online: https: / /www.R-project.org/ (accessed on 1 April 2020).

Simon, Ellen. 2010. Phonological transfer of voicing and devoicing rules: Evidence from L1 Dutch and L2 English conversational speech. Language Sciences 32: 63-86. [CrossRef]

Simonet, Miquel. 2010. Dark and clear laterals in Catalan and Spanish: Interaction of phonetic categories in early bilinguals. Journal of Phonetics 38: 663-78. [CrossRef]

Simonet, Miquel. 2014. Phonetic consequences of dynamic cross-linguistic interference in proficient bilinguals. Journal of Phonetics 43: 26-37. [CrossRef]

Simonet, Miquel, and Mark Amengual. 2020. Increased language co-activation leads to enhanced cross-linguistic phonetic convergence. International Journal of Bilingualism 24: 208-21. [CrossRef]

Tomé Lourido, Gisela, and Bronwen G. Evans. 2021. Sociolinguistic Awareness in Galician Bilinguals: Evidence from an Accent Identification Task. Languages 6: 53. [CrossRef]

Wells, John Christopher. 1982. Accents of English: The British Isles. Cambridge: Cambridge Univ. Press.

Welsh Government. 2012. Welsh Speakers by Local Authority, Gender and Detailed Age Groups, 2011 Census. Available online: https:/ / statswales.gov.wales/Catalogue/Welsh-Language/Census-Welsh-Language/welshspeakers-by-localauthoritygender-detailedagegroups-2011census (accessed on 21 March 2021).

Welsh Government. 2020. Summary Statistics for North Wales Region: 2020. Available online: https://gov.wales/sites/default/files/ statistics-and-research/2020-05/summary-statistics-north-wales-region-2020-806.pdf (accessed on 21 March 2021).

Williams, Angie, Peter Garrett, and Nikolas Coupland. 1996. Perceptual dialectology, folklinguistics, and regional stereotypes: Teachers' perceptions of variation in Welsh English. Multilingua 15: 171-200. [CrossRef]

Wilson, Charles. 2014. The English of Welsh-Speakers: Extralinguistic Factors That Influence the Choice of Phonological Variant. Unpublished Master's dissertation, University of London, London, UK. 